\title{
Dietary intake and development of a quantitative FFQ for a nutritional intervention to reduce the risk of chronic disease in the Navajo Nation
}

\author{
Sangita Sharma ${ }^{1, *}+$, Mihokom Yacavone ${ }^{1,+}, \mathrm{Xia} \mathrm{Cao}^{1}$, Marla Pardilla ${ }^{2}$, Muge Qi ${ }^{2}$ and \\ Joel Gittelsohn ${ }^{2}$ \\ 'Cancer Etiology Program, Cancer Research Center of Hawaii, University of Hawaii, 1236 Lauhala Street, \\ Honolulu, HI 96813, USA: ${ }^{2}$ Center for Human Nutrition, Bloomberg School of Public Health, The Johns Hopkins \\ University, 615 N. Wolfe Street, Baltimore, MD 21205, USA
}

Submitted 29 May 2008: Accepted 26 January 2009: First published online 28 0ctober 2009

\begin{abstract}
Objectives: To characterize dietary intake for Navajo adults, to identify foods for a nutritional intervention programme and to develop a culturally appropriate quantitative FFQ (QFFQ) for evaluating the impact of the intervention programme. Design: A cross-sectional study was conducted using $24 \mathrm{~h}$ dietary recalls. Setting: Navajo Nation, USA.

Subjects: Seventy-nine (forty men, thirty-nine women) aged 18-71 years completed $24 \mathrm{~h}$ dietary recalls.

Results: The median daily energy intake was $11585 \mathrm{~kJ}(2769 \mathrm{kcal})$ for men and $8519 \mathrm{~kJ}(2036 \mathrm{kcal})$ for women. The greatest contributors to energy were fried potato dishes, sweetened juices/drinks, regular pop, bread, tortillas and burritos (contributing approximately $30 \%$ of total energy intake). The mean number of meat servings was over twice that recommended (2-3 servings recommended $v$. $7 \cdot 4$ consumed by men and $5 \cdot 3$ by women). The mean servings of vegetables were well below the recommendation of $3-5$ servings ( $1 \cdot 0$ serving for men and $1 \cdot 2$ servings for women). The final QFFQ contains 177 food and drink items. Conclusions: Our study found that major contributors to total energy, fat and sugar intakes in the Navajo Nation included mostly processed meats and sweetened drinks. A nutritional intervention will target these foods and promote acceptable and healthier alternatives. In addition, we were able to identify foods and beverages for inclusion on a culturally appropriate QFFQ to assess dietary intake. This QFFQ will be used to evaluate the effectiveness of our intervention on food and food group consumption and nutrient intake.
\end{abstract}

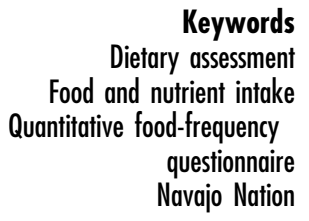

Keywords Food and nutrient intake questionnaire Navajo Nation
Obesity and diet-related chronic disease affect disadvantaged minority groups, especially American Indians, at greater rates than other populations in the USA. In 2003-4, the prevalence of obesity was $32.9 \%$ for all races ${ }^{(1)}$ compared with $40 \cdot 1 \%$ and $37 \cdot 7 \%$ for American Indian and Alaskan Native (AI/AN) men and women, respectively ${ }^{(2)}$. Individuals with obesity are at greater risk for developing chronic disease such as CVD and type 2 diabetes mellitus $(\mathrm{DM})^{(3)}$. Among American Indians, CVD is the leading cause of death; 36\% of American Indians under 65 years of age die of $\mathrm{CVD}^{(4,5)}$. The alarming increase in DM in the USA is a consequence of the obesity epidemic, but DM has been a

† Current address: Nutrition Research Institute, University of North Carolina at Chapel Hill, 500 Laureate Way, Rm\#4201, Kannapolis, NC 28081, USA.

+ Current address: 911 Crater Place \#4, Honolulu, HI 96816, USA. more recent condition among American Indians. For example, only one case of DM was noted in more than 6000 hospitalizations among the Navajo Nation in $1937^{(6)}$. However, by $1992,22 \cdot 9 \%$ of Navajos over the age of 20 years were reported to have DM, which was four times greater than the rate in the age-adjusted US population at that time $^{(6)}$. AI/AN had the highest incidence rate for DM than any other US ethnic group in $2001^{(7)}$, and their mortality rate was threefold greater compared with all US races ${ }^{(8)}$. In 2004, $69 \cdot 6 \%$ of $\mathrm{AI} / \mathrm{AN}$ diagnosed with $\mathrm{DM}$ were obese ${ }^{(9)}$. The American Diabetes Association reports that the average cost of diabetes care is more than \$US 13000 per patient per year ${ }^{(10)}$. However, the Indian Health Services (IHS) per capita personal health-care expenditure for $\mathrm{AI} / \mathrm{AN}$ patients is only $\$ \mathrm{US} 2133^{(7)}$. Given that the limited resources of IHS are used mostly for treatment and that treatment costs are high, a far more cost-effective strategy 
would be to focus efforts on nutritional intervention programmes for prevention of obesity, diabetes and chronic diseases in this high-risk population. Substantial evidence suggests that improving diet and nutrition could reduce the risk of diabetes, cancer and CVD, which would result in decreasing the incidence, mortality and economic cost of these chronic diseases ${ }^{(11-18)}$.

The Navajo Healthy Store (NHS) intervention programme was designed to improve dietary quality and reduce risk for obesity by increasing the availability, purchase and consumption of healthy foods for the Navajo Nation. An effective nutritional intervention programme must target the foods that are commonly consumed and make a substantial contribution to the nutrients of concern for the population. Limited dietary data are available for the Navajo Nation. The Navajo Health and Nutrition Survey (NHNS) was administered between 1991 and 1992 and described the population's nutritional status and overall dietary intake using data collected from $24 \mathrm{~h}$ recalls ${ }^{(19)}$. However, there have been no recent studies on dietary intakes of Navajo adults. Furthermore, a culturally appropriate dietary assessment instrument that includes commonly consumed foods and measures long-term intake is needed to monitor dietary changes before and after a nutritional intervention in order to determine the programme's effectiveness ${ }^{(20)}$. The FFQ is the favoured dietary assessment instrument for measuring usual dietary intake $\mathrm{C}^{(20,21)}$. The literature shows that describing usual frequency of food consumption is easier for respondents than describing the detailed food intake of a specific meal $^{(21-24)}$. The relatively inexpensive cost to administer an FFQ is a great asset, especially for studies with a large sample population. To our knowledge, there is no up-todate comprehensive dietary assessment instrument that assesses total food and nutrient intake for Navajo adults.

The aims of the present study were to: (i) characterize the dietary intake of Navajo adults using data obtained from detailed $24 \mathrm{~h}$ dietary recalls; (ii) highlight specific foods that could be targeted for the nutritional intervention programme; and (iii) develop a culturally appropriate quantitative FFQ (QFFQ) to evaluate the effectiveness of the programme.

\section{Setting}

The Navajo Nation has over 270000 tribal members ${ }^{(25)}$ and occupies the largest federally recognized reservation with more than 16 million acres covering parts of Arizona, New Mexico and Utah ${ }^{(26,27)}$. The unemployment rate on the Navajo Nation is $54 \cdot 1 \%{ }^{(28)}$, which is almost ten times higher than the overall US unemployment rate ${ }^{(29)}$. Access to fruits and vegetables on the reservation is limited mainly by cost, availability, shelf-life and remoteness ${ }^{(3,6,30)}$. There are ten shopping centres with supermarkets on the reservation, but people without transportation or who live far away often rely on gas station stores, convenience stores and trading posts, which have a limited selection of foods ${ }^{(30)}$. Because of the low employment rate, more than $42 \cdot 9 \%$ of Navajos live below the national poverty level with an annual per capita income of \$US 7724, which is almost four times lower than the US average ${ }^{(28)}$. In 2000, approximately $37 \%$ of the housing units in the Navajo Nation lacked the electricity necessary for refrigeration and cooking ${ }^{(30-32)}$. Therefore, perishable foods (e.g. dairy products, fruits and vegetables) and foods that require cooking are difficult to store ${ }^{(3,30,31)}$.

\section{Experimental methods}

\section{$24 \mathrm{~b}$ Dietary recalls}

Collection of $24 \mathrm{~h}$ dietary recalls was conducted in all five agencies of the Navajo Nation. Agencies are the 'states' within the Navajo Nation. There are five agencies on the Navajo Nation. Each is a separate administrative 'unit' below the tribal government.

Field workers recruited participants at community centres (i.e. chapter houses), senior centres, laundromats, trading posts, grocery stores, flea markets and Navajo Nation offices. Recruitment sites were chosen to represent various geographic areas, assess all food outlets and capture people from all age groups (19-90 years) and sexes. Pregnant and lactating women were excluded.

The two interviewers were local field workers who spoke both Navajo and English. Interviewers were trained for a total of $5 \mathrm{~d}$. At the end of training, both interviewers were required to successfully conduct several mock interviews in order to become certified. The certification helped standardize interview techniques such as prompting for easily forgotten foods like sweets, snacks and alcohol. In addition, a manual of procedures was created to ensure all data were collected using a standardized approach.

The collection of dietary recalls was conducted after the participant signed the written informed consent form for the study. The interviewers recorded all drinks and foods consumed in the past $24 \mathrm{~h}$. Additionally, they obtained and recorded the time of consumption, the types of foods and drinks (e.g. type of meat), the brand names, where the foods/drinks were obtained and any additions (e.g. butter on bread, sugar in coffee).

Each interviewer was given a set of three-dimensional manufactured food models (NASCO Company, Fort Atkinson, WI, USA) as well as models created by field workers of foods eaten locally (e.g. Navajo tortillas and burritos). All food models were carefully chosen with input from local field workers to best represent portion sizes of foods that are commonly consumed by adult Navajo. Additionally, the interviewers used familiar household units (e.g. bowls, spoons and cups), standard units (e.g. a slice of bread) and food packaging from the stores (e.g. packets of crisps (chips), sunflower seeds and chocolate bars) to best estimate the usual amounts consumed. Participants were given the freedom to use food models, household utensils and standard units to describe their portion sizes. 
One $24 \mathrm{~h}$ recall was conducted per participant and included additional questions to prompt for easily forgotten foods. At the end of the recall, participants were asked whether they were following any special diet, such as a low-fat or weight-reduction diet. The project coordinator reviewed all collected data and asked the interviewers to re-contact the participants to obtain any missing information. The recall data were collected on both weekdays and weekend days during the period from October 2006 until February 2007. All participants received a \$US 20 gift card upon completion of the recall.

\section{Portion weights}

Because no published data were available, a nutrition researcher weighed portions for all reported foods in order to derive weights for portion sizes reported in the $24 \mathrm{~h}$ recalls. For example, ten Navajo tortillas from various sources, including hand-made/home-made, were weighed, and the average weights were obtained. All of the weights were measured using an electronic kitchen scale (Aquatronic Baker's Dream Scale; Salter Houseware Ltd, Oak Brook, IL, USA). All data were entered into an Excel spreadsheet (Microsoft Corporation, Redmond, WA, USA) to calculate the average weights.

\section{Data analysis}

The $24 \mathrm{~h}$ recall data were coded and input by a graduate nutrition student and analysed using the Nutribase Clinical Nutrition Manager software version 5·18 (CyberSoft Inc., Phoenix, AZ, USA). Nutribase Clinical calculated the nutrient intake and food group servings per person using values from the US Department of Agriculture (USDA) food composition table.

Similar foods, such as different types of crisps or soft drinks, were combined to highlight foods for the NHS intervention programme and to identify foods that contributed significantly to the sample's intakes of energy, fat and sugar. Descriptive analysis of dietary intake and food sources was undertaken using the SAS software package version 9·1 (SAS Institute, Inc., Cary, NC, USA).

\section{Development of the $Q F F Q$}

In order to develop a culturally appropriate QFFQ, three components were considered: (i) a comprehensive food list; (ii) portion sizes for each food/drink item; and (iii) categorization of consumption frequencies for each food listed in the $\mathrm{QFFQ}^{(21,33)}$.

All foods and drink items reported in $24 \mathrm{~h}$ recalls by two or more respondents were included in the pilot QFFQ. Seasonal foods and NHS promoted foods that were not reported in the $24 \mathrm{~h}$ recalls were added after discussion with local field workers, who were Navajo. Condiments and spices that had minimum contribution to nutrients were excluded. The pilot QFFQ also included foods that were not reported in the recalls but would be targeted in the intervention, such as baked crisps and high-fibre cereals.

Similar foods, such as crisps and pasta dishes, were grouped together. Foods were grouped under appropriate food groups like breads, cereals and fruits. Careful attention was given to the ordering of the food list so that it made sense culturally. Appropriate food portion sizes and models for each food were also incorporated. Local field workers aided in determining portion size and developing food models that were unique to the population, such as tamales, Navajo burgers and roast mutton sandwiches. To ensure that no food/drink items were omitted on the questionnaire, additional blank lines were provided for the respondents to add any missing items to the pilot QFFQ. The pilot QFFQ was administered to thirty participants in the Navajo Nation. No additional foods or drinks were reported by respondents. In order to improve the QFFQ, pilot respondents were also asked how they felt about the length of the instrument, the appropriateness of the food models and portion sizes, and their overall assessment of the instrument. Informed consent was obtained from all participants, and the study was approved by the Johns Hopkins Bloomberg School of Public Health Committee on Human Research, as well as the Navajo Nation Internal Review Board.

\section{Results}

\section{Dietary intake}

Forty men and thirty-nine women completed the $24 \mathrm{~h}$ recalls. An accurate response rate could not be calculated as the interviewers failed to keep detailed logs of the response from the subjects despite instructions to do so. However, the interviewers believe that approximately one-third of all participants approached for interviews refused. One recall (female) with a total energy intake of $1247 \mathrm{~kJ}$ ( $298 \mathrm{kcal}$ ) was excluded from the nutrient analysis because the interviewer did not feel this respondent gave a thorough recall. Therefore, nutrient analysis was conducted on a total of seventy-eight participants (forty men and thirty-eight women).

Table 1 presents mean and median daily energy, macroand micronutrient intakes of men and women of the Navajo Nation. For comparison, the Navajo Health and Nutrition Survey (NHNS) 1991-92, which also used $24 \mathrm{~h}$ recalls to measure dietary intake, is presented. We chose the age group from the NHNS closest to the median age in our study.

Of the respondents, 15\% reported being on a special diet (four males and eight females), mainly low-energy and diabetic diets.

Comparing the median dietary intakes of our data and the NHNS data, intakes of total energy and macronutrients such as carbohydrate, protein and fat were higher in our data. On the contrary, micronutrient intakes for men and women, such as total folate and $\mathrm{Zn}$, were 
Table 1 Daily energy and nutrient intakes of adult Navajo men and women, October 2006-February 2007, compared with data from the Navajo Health and Nutrition Survey (NHNS) ${ }^{(19)}$

\begin{tabular}{|c|c|c|c|c|c|c|c|c|c|c|c|c|}
\hline & \multicolumn{6}{|c|}{ Men } & \multicolumn{6}{|c|}{ Women } \\
\hline & \multicolumn{3}{|c|}{$\begin{array}{c}\text { Navajo } 18-70 \text { years } \\
(n 40)\end{array}$} & \multicolumn{2}{|c|}{$\begin{array}{c}\text { NHNS } 20-39 \text { years } \\
(n 157)\end{array}$} & \multirow[b]{2}{*}{ DRI } & \multicolumn{3}{|c|}{$\begin{array}{c}\text { Navajo } 20-71 \text { years } \\
(n \text { ) 38) }\end{array}$} & \multicolumn{2}{|c|}{$\begin{array}{l}\text { NHNS } 40-59 \text { years } \\
(n 163)\end{array}$} & \multirow[b]{2}{*}{ DRI } \\
\hline & Mean & SD & Median & Mean & Median & & Mean & SD & Median & Mean & Median & \\
\hline Age (years) & 34 & 15 & 30 & N/A & $N / A$ & & 45 & 15 & 45 & $\mathrm{~N} / \mathrm{A}$ & N/A & \\
\hline Energy (kJ) & 16498 & 14125 & 11585 & 8899 & 7991 & $N / A$ & 9029 & 4268 & 8519 & 7146 & 6510 & $N / A$ \\
\hline Fat $(\mathrm{g})$ & 158 & 146 & 97 & 81 & 72 & $N / A$ & 86 & 54 & 74 & 67 & 61 & $N / A$ \\
\hline Saturated fat (g) & 46 & 41 & 36 & 26 & 23 & $\leq 25^{\star}$ & 25 & 16 & 20 & 22 & 19 & $\leq 20^{*}$ \\
\hline Protein $(g)$ & 116 & 80 & 85 & 83 & 71 & $56+$ & 74 & 37 & 75 & 73 & 65 & $46 \dagger$ \\
\hline Carbohydrate (g) & 490 & 425 & 363 & 267 & 238 & 130 & 273 & 129 & 236 & 206 & 194 & 130 \\
\hline Sugar (g) & 252 & 311 & 167 & $\mathrm{~N} / \mathrm{A}$ & $\mathrm{N} / \mathrm{A}$ & $\leq 156^{\star}$ & 116 & 83 & 105 & $\mathrm{~N} / \mathrm{A}$ & $\mathrm{N} / \mathrm{A}$ & $\leq 125^{\star}$ \\
\hline Dietary fibre (g) & 25 & 19 & 19 & 15 & 11 & $38 \ddagger, \S$ & 16 & 11 & 13 & 13 & 11 & $25 \ddagger, \S$ \\
\hline Vitamin A ( $\mu \mathrm{g} R E)$ & 628 & 801 & 306 & 763 & 405 & 900 & 463 & 561 & 257 & 686 & 330 & 700 \\
\hline Vitamin $B_{6}(\mathrm{mg})$ & $1 \cdot 4$ & $1 \cdot 2$ & $1 \cdot 1$ & $1 \cdot 6$ & $1 \cdot 0$ & $1 \cdot 3 \|$ & $1 \cdot 0$ & 0.7 & 0.9 & $1 \cdot 3$ & 0.9 & $1 \cdot 3 \|$ \\
\hline Vitamin C (mg) & 133 & 184 & 51 & 113 & 47 & 90 & 64 & 75 & 39 & 85 & 40 & 75 \\
\hline Total folate $(\mu \mathrm{g})$ & 187 & 228 & 92 & 250 & 172 & 400 & 145 & 221 & 69 & 183 & 136 & 400 \\
\hline $\mathrm{Ca}(\mathrm{mg})$ & 881 & 629 & 684 & 560 & 438 & $1000 \pm, \uparrow$ & 616 & 614 & 376 & 378 & 310 & $10004, \mathrm{t \dagger}$ \\
\hline $\mathrm{Fe}(\mathrm{mg})$ & 20 & 16 & 14 & 16 & 13 & 8 & 15 & 12 & 11 & 14 & 12 & $18+t$ \\
\hline Zn (mg) & 10 & 6 & 8 & 12 & 10 & 11 & 9 & 9 & 6 & 10 & 9 & 8 \\
\hline Alcohol (g) & 18 & 52 & 0 & $\mathrm{~N} / \mathrm{A}$ & $\mathrm{N} / \mathrm{A}$ & $N / A$ & 2 & 10 & 0 & $\mathrm{~N} / \mathrm{A}$ & $\mathrm{N} / \mathrm{A}$ & $N / A$ \\
\hline$\%$ energy from fat & 35 & 11 & 34 & 34 & 35 & $20-35^{\star \star}$ & 34 & 11 & 36 & 34 & 34 & $20-35^{\star *}$ \\
\hline$\%$ energy from carbohydrate & 51 & 12 & 53 & 50 & 48 & $45-65^{\star \star}$ & 52 & 11 & 52 & 49 & 48 & $45-65^{\star *}$ \\
\hline$\%$ energy from protein & 13 & 3 & 12 & 16 & 15 & $10-35^{\star *}$ & 14 & 4 & 14 & 17 & 16 & $10-35^{\star *}$ \\
\hline$\%$ energy from alcohol & 3 & 5 & 0 & $\mathrm{~N} / \mathrm{A}$ & $\mathrm{N} / \mathrm{A}$ & $N / A$ & 0 & 1 & 0 & $\mathrm{~N} / \mathrm{A}$ & $\mathrm{N} / \mathrm{A}$ & $N / A$ \\
\hline
\end{tabular}

RE, retinol equivalents; N/A, not available.

DRI, Dietary Reference Intake values are from the US Department of Agriculture's Dietary Guidelines for Americans, 2005 ${ }^{(43)}$; values in roman (upright) font are Recommended Dietary Allowances (RDA). *Based on total energy intake of $10460 \mathrm{~kJ} / \mathrm{d}(2500 \mathrm{kcal} / \mathrm{d})$ for men and $8368 \mathrm{~kJ} / \mathrm{d}(2000 \mathrm{kcal} / \mathrm{d})$ for women.

tBased on $\mathrm{g}$ protein $/ \mathrm{kg}$ body weight for the reference body weight, e.g. for adults $0.8 \mathrm{~g} / \mathrm{kg}$ body weight for the reference body weight.

fAdequate Intake (Al). RDA and Al may both be used as goals for individual intake. The RDA is set to meet the needs of almost all (97 to $98 \%$ ) individuals in a group. The Al is expected to meet or exceed the amount needed to maintain a defined nutritional state of essentially all members of a population.

$\S$ For $>51$ years, $30 \mathrm{~g}$ for men and $21 \mathrm{~g}$ for women.

IIFor $>51$ years, $1.7 \mathrm{mg}$ for men and $1.5 \mathrm{mg}$ for women.

F For $>51$ years, $1200 \mathrm{mg}$ for both sexes.

${ }^{* *}$ Acceptable Macronutrient Distribution Range ${ }^{(34)}$

$\mathrm{t}+\mathrm{For}>51$ years, $8 \mathrm{mg}$ for women. 
lower than the NHNS data. Among women, our data were lower in vitamin $\mathrm{C}$ and Fe than the NHNS data. When compared with the Dietary Reference Intake (DRI) ${ }^{(34)}$, only vitamin $\mathrm{B}_{12}$ exceeded the recommendation in our study (data not presented). The median percentages of energy from fat for men and women in our data were $34 \%$ and $36 \%$, respectively. For both genders, the median percentage of energy from protein was lower for our data than for the NHNS data.

The top five food sources of energy, fat and sugar derived from the $24 \mathrm{~h}$ recalls are summarized in Table 2 . The top sources of energy for the Navajo adults were fried potato dishes, sweetened juices/drinks, soft drinks, bread, and Navajo tortillas and burritos. The top two contributors to fat for Navajo adults were fried potato dishes and hot dogs and sausages, which were also included in the top five energy sources. Other sources of fat were egg dishes, crisps and popcorn, and hamburgers. The top four sources of sugar, which contributed $64 \%$ of the sugar intake, were beverages: soft drinks, sweetened juices/drinks, unsweetened juices/drinks and beer.

Table 3 presents the mean and median number of servings of each food group consumed by the Navajo adults. Fruit and vegetable intake was far less than the USDA recommendation for both genders, and women also did not meet the recommended servings of dairy intake. Meat and meat alternatives, sweets, oil and sugar groups were consumed above the recommendation for both men and women (data not presented for the latter four groups).

\section{Development of the quantitative FFQ}

The final Navajo QFFQ includes 177 items (twenty-seven breads, twenty-one vegetables, sixteen fruits, thirteen beverages, ten soups or stews, four cereals, fourteen dairy and eggs, eight rice or pasta dishes, thirty-three meat, chicken or fish dishes, twenty-seven desserts and snacks, and four alcoholic beverages; Appendix 1) with a recall period of $30 \mathrm{~d}$. Eight categories are used to measure frequency of consumption ranging from 'Never or less than one time in 30 days' to 'Two or three times a day'. Appendix 2 presents a sample of our final QFFQ. Portion size is assessed using familiar household units, food models and standard units for each item listed. The developed QFFQ takes approximately $45 \mathrm{~min}$ to be administered by a trained interviewer.

\section{Discussion}

To develop a successful nutritional intervention programme, it is crucial to know the nutrient intake of the population and food sources of nutrients. One aim of the NHS intervention programme was to identify major foods that contributed to energy, fat and sugar and to replace these with acceptable and comparable lower-fat and/or

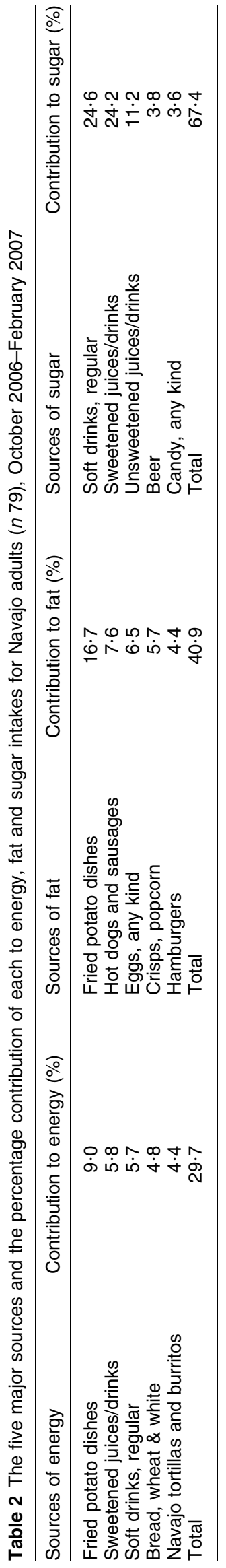


Table 3 Daily servings of food groups consumed by Navajo adults, October 2006-February 2007

\begin{tabular}{|c|c|c|c|c|c|c|c|}
\hline \multirow[b]{2}{*}{ Food group } & \multirow[b]{2}{*}{ Recommended number of servings* } & \multicolumn{3}{|c|}{ Men $(n$ 40) } & \multicolumn{3}{|c|}{ Women (n 38) } \\
\hline & & Mean & SD & Median & Mean & SD & Median \\
\hline Dairy & 3 & $3 \cdot 2$ & $7 \cdot 6$ & $1 \cdot 5$ & $1 \cdot 0$ & $1 \cdot 9$ & $0 \cdot 1$ \\
\hline Meat and meat alternatives & $5-7$ & $7 \cdot 4$ & $8 \cdot 7$ & $4 \cdot 3$ & $5 \cdot 3$ & $4 \cdot 4$ & $4 \cdot 4$ \\
\hline Vegetables & $4-8$ & $1 \cdot 0$ & $1 \cdot 4$ & 0.2 & $1 \cdot 2$ & 1.9 & $0 \cdot 2$ \\
\hline Fruits & $3-5$ & $2 \cdot 9$ & $8 \cdot 5$ & 0.0 & $1 \cdot 3$ & $3 \cdot 1$ & $0 \cdot 0$ \\
\hline Grain & $5-10$ & $8 \cdot 9$ & $5 \cdot 8$ & $8 \cdot 3$ & $6 \cdot 7$ & $5 \cdot 1$ & $5 \cdot 0$ \\
\hline
\end{tabular}

*The US Department of Agriculture's Dietary Guidelines for Americans, 2005(43) recommends 5-7 servings grain, 4-6 servings vegetables, 3-4 servings fruit, 3 servings dairy and 5-6 oz of meat or meat alternatives for a daily energy intake of 6699-9205 kJ (1601-2200 kcal); 8-10 servings of grain, 6-7 servings vegetables, $4-5$ servings fruit, 3 servings dairy and 6-7 oz of meat or meat alternatives for a daily energy intake of 9210-11716 kJ (2201-2800 kcal); 10 servings of grain, 8 servings of vegetables, 5 servings fruit, 3 servings dairy and 7 oz of meat or meat alternatives for a daily energy intake above $11716 \mathrm{~kJ}$ $(2800 \mathrm{kcal})$. The table presents the range of servings of each food group for a daily energy intake of $6695-13390 \mathrm{~kJ}(1600-3200 \mathrm{kcal})$.

lower-sugar food items. Therefore, dietary data obtained from the $24 \mathrm{~h}$ recalls were used to develop this multilevel intervention programme to reduce obesity and diet-related chronic disease among Navajo adults. Our study found that fruit and vegetable intakes were low. Major contributors to total energy, fat and sugar included regular soft drinks, hot dogs and sausages, fried potato dishes, sweetened drinks and crisps. Many of these food items could potentially be replaced by healthier alternative items such as water, low-fat sausages, baked crisps and unsweetened juice or sugar-free drinks. To reduce energy and fat intakes, healthier cooking methods, such as baking and steaming, could be promoted over deep-frying and pan-frying. Additionally, the $24 \mathrm{~h}$ recalls identified locally consumed acceptable foods, such as traditional foods, that will aid in the development of a culturally appropriate intervention programme. Through the planned healthy stores programme, many of these alternative food items, such as baked crisps, water/ diet soft drinks, low-sugar/high-fibre cereals and cooking spray, will be introduced through community-wide media, shelf labels, posters, flyers and in-store taste testing sessions. Both large and small food stores on the Navajo Nation will be encouraged to stock these promoted foods for purchase.

The Navajo Nation is large (more than 16 million acres) and up-to-date, reliable housing maps were not available for sampling purposes. As the aim of the present work was to include all foods consumed by the population, we sampled geographically to capture the diversity in diet resulting from differential access to and availability of foods. We targeted specific areas of the Navajo Nation and randomly sampled within those areas. We included subjects aged between 19 and 90 years. Because of the small number of people within each age-sex group we did not present dietary intake by age group, nor did we present a table illustrating the age/ gender/area distribution of the participants.

Pilot QFFQ respondents were selected from places close to the food store areas because the store provides the majority of all foods consumed. It is possible we omitted some foods, as it is the same sampling method we used initially. However, the purpose of the work was not to include $100 \%$ of foods consumed. Actually, most FFQ only capture $85 \%$.
Although our main purpose was not to assess dietary adequacy, nutrient analysis from the $24 \mathrm{~h}$ recalls provided insight into the nutritional intake of the study population. The mean energy intakes for the Navajo male and female participants were $16498 \mathrm{~kJ}$ (3943 kcal) and $9029 \mathrm{~kJ}$ (2158 kcal), respectively. These findings are much higher than the mean energy intakes reported by the 1991-2 NHNS study ${ }^{(19)}$ and the 1999-2000 National Health and Nutrition Examination Survey (men aged 20-39 years: $11832 \mathrm{~kJ}(2828 \mathrm{kcal})$; women aged $40-59$ years: $7648 \mathrm{~kJ}$ $(1828 \mathrm{kcal}))^{(35)}$. Moreover, the mean percentage of energy from alcohol in the present study was $3 \cdot 1 \%$ for men and $0.4 \%$ for women.

The NHNS study reported that vitamin A, vitamin C, folate, $\mathrm{Ca}$ and $\mathrm{Fe}$ were low among their survey participants and that these nutrients had been consistently low among Navajo adults in the past ${ }^{(19)}$. Approximately 15 years later, our study results indicate that these nutrients continue to be low despite the increase in total energy intake. The only nutrient that was above the DRI ${ }^{(34)}$ was Fe for men. This indicates that the foods consumed by Navajo adults continue to be high in energy but less nutrient-dense.

Regular soft drinks and sweetened juices/drinks accounted for $11.5 \%$ of the total energy intake and are the leading contributor to energy, as also found by prior studies conducted among American Indians ${ }^{(36,37)}$. Sweetened beverage consumption was noted to be high throughout the year among American Indians, with increased intake during the summer due to the high temperature and dry climate ${ }^{(36,38)}$. Similar results were reported by two other American Indian studies conducted in Arizona, which reported that sweetened beverages comprised 14\% and $11 \%$ of total energy intake ${ }^{(37,38)}$. The NHNS study, in which $24 \mathrm{~h}$ recalls were collected throughout the year, showed that sweetened beverage consumption comprised $7 \%$ of total energy intake ${ }^{(19)}$ compared with our $11.5 \%$, showing a possible increase over the last 15 years.

Overall, our results were consistent with other American Indian studies which showed a high consumption of less nutrient-dense foods ${ }^{(19,36-42)}$. However, the actual foods consumed may have changed over time and thus 
the previous dietary assessment tools cannot be used. Changes in economic status, environment and food availability necessitate the development of updated assessment tools to reflect current diet.

We previously reported that crisps, popcorn and fry bread were the highest contributors to energy for Apache adults $^{(39)}$. However, these food items did not appear among the top five contributors to energy in the present Navajo study nor in a study conducted among Havasupai adults in Arizona by Vaughan et $a l^{(38)}$. Cheese was reported to be one of the top five contributors to energy for the latter study ${ }^{(38)}$, but was not one of the top five contributors among the Navajo or Apache populations in our studies ${ }^{(39)}$. This shows that American Indian tribes are actually distinct cultural entities, and variation in dietary intake exists between the same tribes residing in the same state. Therefore, it is necessary to develop culturally specific dietary assessment instruments.

One strength of our instrument is that it was driven by the study population. Thus, it followed a logical order that enhanced their recall of food and drink items. For example, study participants almost always added sugar/ artificial sweeteners to coffee/tea/iced tea. Therefore, sugar/artificial sweeteners were placed under the category of 'beverages' on the QFFQ to strengthen the study participants' recall of the items, rather than being placed in a separate category. Gravy was a single miscellaneous item that is consumed on biscuits as a snack food; therefore, it was grouped under 'desserts and snacks'. 'Muffin' was grouped under 'desserts and snacks' as advised by Navajo participants. Another strength is the ability of our instrument to measure food and food group consumption and nutrient intake, which allowed for the assessment of dietary adequacy (excess or deficiency). In addition, the QFFQ measured consumption frequency of each food/drink item. With these data, we can track changes in consumption of foods that are promoted and de-promoted by the programme (e.g. crisps and regular soft drinks) pre- and post-intervention.

The limitations of the study were the small sample size and the utilization of a single $24 \mathrm{~h}$ recall in estimating nutrient intake. However, the main purpose of the recalls was to identify foods to be included in the QFFQ and to highlight foods for the intervention programme. Upon completing the pilot QFFQ, participants were asked to add any missing foods that were not included in the questionnaire, and no food was identified as missing. Therefore, the $24 \mathrm{~h}$ recalls did provide adequate information to identify foods for inclusion in the final Navajo $\mathrm{QFFQ}^{(39)}$. The sample for the $24 \mathrm{~h}$ recall was not exclusively random and may not be representative of all the Navajo Nation. However, our sample frame was stratified by age, gender and geographic area to ensure recruitment of respondents with various economic circumstances and a wide range of food intakes. A validation study for this QFFQ is underway.

\section{Conclusion}

Our study found that major contributors to total energy, fat and sugar intakes in the Navajo Nation included mostly processed meats and sweetened drinks. A nutritional intervention will target these foods and promote acceptable and healthier alternatives. In addition, we were able to identify foods and beverages for inclusion on a culturally appropriate QFFQ to assess dietary intake. This QFFQ will be used to evaluate the effectiveness of our intervention on food and food group consumption and nutrient intake. We will also be able to determine changes in the types, frequencies and portions of all foods before and after the nutritional intervention.

\section{Acknowledgements}

Sources of funding: The research was supported by the National Research Initiative of the USDA Cooperative State Research, Education and Extension Service. Conflict of interest: No conflict of interest was reported from the authors. Authorship responsibilities: S.S. was responsible for the overall study, including organizing the study, training interviewers for the $24 \mathrm{~h}$ recall and pilot QFFQ, monitoring data collection and analysis, and writing the manuscript. M.M.Y. entered recall and portion weight data and assisted in writing the manuscript. X.C. collected portion size data, supervised data entry/analysis and also aided in writing the manuscript. M.P. coordinated the project, collected $24 \mathrm{~h}$ recalls and pilot QFFQ, and provided substantial input into the questionnaire design, data collection and writing of the manuscript. M.Q. also contributed substantially with questionnaire design, data collection and writing of the manuscript. J.G. is the principal investigator of Navajo Healthy Store intervention programme and gave advice on data collection, questionnaire design, data analysis and writing of the manuscript. Acknowledgements: We would like to extend our appreciation to the Navajo Nations community members and the Bashas supermarket. The authors are grateful for all the assistance received from staff and students during this study.

\section{References}

1. Department of Health and Human Services, Centers for Disease Control and Prevention (2007) Overweight and Obesity. http://www.cdc.gov/nccdphp/dnpa/obesity/ index.htm (accessed May 2007).

2. Department of Health and Human Services (2003) Health status of American Indians compared with other racial/ ethnic minority populations - selected states, 2001-2002. MMWR Morb Mortal Wkly Rep 52, 1148-1152.

3. Story M, Evans M, Fabsitz RR et al. (1999) The epidemic of obesity in American Indian communities and the need for childhood obesity-prevention programs. Am J Clin Nutr 69, Suppl. 4, S747-S754.

4. Department of Human Health and Services, Division for Heart Disease and Stroke Prevention, Centers for Disease 
Control and Prevention (2007) American Indian and Alaska Native Heart Disease and Stroke Facts. http://www. cdc.gov/DHDSP/library/fs_aian.htm (accessed November 2007).

5. Oh SS, Croft JB, Greenlund KJ et al. (2004) Disparities in premature deaths from heart disease -50 states and the District of Columbia. MMWR Morb Mortal Wkly Rep $\mathbf{5 3}$ 121-125.

6. Will JC, Strauss KF, Mendlein JM et al. (1997) Diabetes mellitus among Navajo Indians: findings from the Navajo Health and Nutrition Survey. J Nutr 127, Suppl. 10, S2106-S2113.

7. Department of Health and Human Services, Indian Health Service (2007) Diabetes. http://info.ihs.gov/Files/DiabetesJan2007.doc (accessed November 2007).

8. Department of Health and Human Services, Indian Health Service (2007) Facts on Indian Health Disparities. http:// info.ihs.gov/Files/DisparitiesFacts-Jan2007.doc （accessed November 2007).

9. Wilson C, Gilliland S, Moore K et al. (2007) The epidemic of extreme obesity among American Indian and Alaska Native adults with diabetes. Prev Chronic Dis 4, 06A.

10. American Diabetes Association (2007) Direct and Indirect Costs of Diabetes in the United States. Diabetes Statistics. http://www.diabetes.org/diabetes-statistics/cost-of-diabetesin-us.jsp (accessed November 2007).

11. Ahmed FE (2004) Effect of diet, life style, and other environmental/chemopreventive factors on colorectal cancer development, and assessment of the risks. J Environ Sci Health C Environ Carcinog Ecotoxicol Rev 22, 91-147.

12. Eyre H, Kahn R, Robertson RM \& the ACS/ADA/AHA Collaborative Writing Committee (2004) Preventing cancer, cardiovascular disease, and diabetes: a common agenda for the American Cancer Society, the American Diabetes Association, and the American Heart Association. CA Cancer J Clin 54, 190-207.

13. Gundgaard J, Nielsen JN, Olsen J et al. (2003) Increased intake of fruit and vegetables: estimation of impact in terms of life expectancy and healthcare costs. Public Health Nutr 6, 25-30.

14. Key TJ, Schatzkin A, Willett WC et al. (2004) Diet, nutrition and the prevention of cancer. Public Health Nutr 7, 187-200.

15. Van't Veer P, Jansen MCJF, Klerk M et al. (2000) Fruits and vegetables in the prevention of cancer and cardiovascular disease. Public Health Nutr 3, 103-107.

16. Venn BJ \& Mann JI (2004) Cereal grains, legumes and diabetes. Eur J Clin Nutr 58, 1443-1461.

17. Williams MT \& Hord NG (2005) The role of dietary factors in cancer prevention: beyond fruits and vegetables. Nutr Clin Pract 20, 451-459.

18. World Cancer Research Fund/American Institute for Cancer Research (1997) Food, Nutrition and the Prevention of Cancer: A Global Perspective. Washington, DC: AICR.

19. Ballew C, White LL, Strauss KF et al. (1997) Intake of nutrients and food sources of nutrients among the Navajo: findings from the Navajo Health and Nutrition Survey. $J$ Nutr 127, Suppl. 10, S2085-S2093.

20. Teufel NI (1997) Development of culturally competent food-frequency questionnaires. Am J Clin Nutr 65, Suppl. 10, S1173-S1178.

21. Willett W (1998) Nutritional Epidemiology, 2nd ed. New York: Oxford University Press.

22. Smith AF (1993) Cognitive psychological issues of relevance to the validity of dietary reports. Eur J Clin Nutr $\mathbf{4 7}$, Suppl. 2, S6-S18.

23. Smith AF, Jobe JB \& Mingay DJ (1991) Retrieval from memory of dietary information. Appl Cogn Psychol 5, 269-296.

24. Bradburn NM, Rips LJ \& Shevell SK (1987) Answering autobiographical questions: the impact of memory and inference on surveys. Science 10, 157-161.
25. Navajo Nation Washington Office (2008) Navajo Nation Profile. http://www.nnwo.org/navajonationprofile.html (accessed February 2008).

26. Official Site of Navajo Nation (2008) The Navajo Nation History page. http://www.navajo.org/history.html (accessed February 2008)

27. Division of Economic Development, Navajo Nation (2007) Fast Facts. Where is Navajo Nations. http://www. navajobusiness.com/fastFacts/LocationMap.htm (accessed November 2007).

28. Choudhary T (2006) 2005-2006 Comprehensive Economic Development Strategy of the Navajo Nation. http:// www.navajobusiness.com/pdf/CEDS/CEDS\%202005\%20-\% 2006\%20Final.pdf (accessed November 2007).

29. US Department of Labor, Bureau of Labor Statistics (2004) US Unemployment Rates for States. Annual Average Rankings Year: 2004. http://www.bls.gov/lau/lastrk04.htm (accessed November 2007)

30. Lombard KA, Forster-Cox S, Smeal D et al. (2006) Diabetes on the Navajo nation: what role can gardening and agriculture extension play to reduce it? Rural Remote Health 6, 640.

31. Bain C, Ballentine C, DeSouza A et al. (2002) Economic and Social Development Stemming from the Electrification of the Housing Stock on the Navajo Nation. Working Paper Series no. 02-34. Flagstaff, AZ: College of Business Administration, Northern Arizona University.

32. Denetclaw P Jr \& Ahasteen L (2004) Navajo Electrification Demonstration Program. Navajo Tribal Utility Authority. US Department of Energy Tribal Energy Program, 2004 Program Review Meeting, Golden, Colorado, October 20, 2004. http://www.eere.energy.gov/tribalenergy/pdfs/38_ nuta_denetclaw_ahasteen.pdf (accessed December 2007).

33. Shahar D, Fraser D, Shai I et al. (2003) Development of a food frequency questionnaire (FFQ) for an elderly population based on a population survey. J Nutr 133, 3625-3629.

34. Food and Nutrition Board (2006) Dietary Reference Intake: The Essential Guide to Nutrient Requirements. Washington, DC: National Academy Press.

35. Department of Health and Human Services (2004) Trends in intake of energy and macronutrients - United States, 1971-2000. MMWR Morb Mortal Wkly Rep 53, 80-82.

36. Wharton CM \& Hampl JS (2004) Beverage consumption and risk of obesity among Native Americans in Arizona. Nutr Rev 62, 153-159.

37. Teufel NI \& Dufour DL (1990) Patterns of food use and nutrient intake of obese and non-obese Hualapai Indian women of Arizona. J Am Diet Assoc 90, 1229-1235.

38. Vaughan LA, Benyshek DC \& Martin JF (1997) Food acquisition habits, nutrient intakes, and anthropometric data of Havasupai adults. J Am Diet Assoc 97, $1275-1282$.

39. Sharma S, Cao X, Gittelsohn J et al. (2007) Dietary intake and a food-frequency instrument to evaluate a nutrition intervention for the Apache in Arizona. Public Health Nutr 10, 948-956.

40. Taylor CA, Keim KS \& Gilmore AC (2005) Impact of core and secondary foods on nutritional composition of diets in Native-American women. J Am Diet Assoc 105, 413-419.

41. Stang J, Zephier EM, Story M et al. (2005) Dietary intakes of nutrients thought to modify cardiovascular risk from three groups of American Indians: The Strong Heart Dietary Study, Phase II. J Am Diet Assoc 105, 1895-1903.

42. deGonzague B, Receveur O, Wedll D et al. (1999) Dietary intake and body mass index of adults in 2 Ojibwe communities. J Am Diet Assoc 99, 710-716.

43. US Department of Health and Human Services \& US Department of Agriculture (2005) Dietary Guidelines for Americans, 2005, 6th ed. Washington, DC: US Government Printing Office. 


\section{Appendix 1}

Food and drink items listed on the Navajo quantitative FFQ (QFFQ)

\begin{tabular}{ll}
\hline Category & Food items
\end{tabular}

Breads ( $n$ 27)

Vegetables and salad ( $n$ 21)

Fruits (n 16)

Beverages (n 13)

Soups or stews (n 10)

Cereals (n 4)

Dairy and eggs (n 14)

Rice, pasta, etc. ( $n$ 8)

Meat, chicken or fish (n 33)

Desserts and snacks ( $n$ 27)

Alcohol (n 4)
Fry bread; Navajo taco; Any taco; Navajo tortilla, white flour; Navajo tortilla, whole wheat flour or half and half; Navajo burger; Navajo roast mutton sandwich; Pueblo bread or home-made oven bread; Cornbread; Blue corn bread; Burritos egg, bacon, Spam, ground beef, potato, tortilla; Biscuits egg, bacon, Spam, ground beef, potato; Burrito no meat; Burrito with meat; Sausage biscuit; Chimichanga burrito; Tamales; Enchiladas; Hot dog in bun; Rez dog; Whole wheat/wheat bread; White bread; Yeast bread or dinner roll; Doughnut; Pancakes; Waffles; Crackers, Saltines, Ritz

Green beans; Peas; Corn on the cob; Corn; Onions rings, battered and fried; Tomato; Chillies, roasted, raw, fried, grilled, red or green; Carrots; Broccoli or cauliflower; Avocado; Mixed vegetable; Any squash or courgette; Spinach, cabbage, greens; Salad; Coleslaw; Salsa; Any dressing; Fried potato, potato wedges, hash brown potatoes, French fries; Mashed potato; Baked or boiled potato; Potato salad

Banana; Orange or tangerine; Apple; Apple sauce; Grapes; Cantaloupe \& watermelon; Grapefruit; Pears; Strawberry, raspberry, blueberries or chokeberries; Dry fruits, including raisins and trail mix; Peaches, apricot, nectarine; Plums; Kiwi; Mango; Fruit salad; Any canned fruit cocktail

Iced tea with sugar or sweetened or regular iced tea; Iced tea without sugar or unsweetened or diet tea; Hot tea, any kind; Coffee, any kind; Any regular soft drinks, including energy drinks; Any diet soft drinks; Fruit punch drink; Sugar-free punch or drinks; $100 \%$ juice sweetened; $100 \%$ juice unsweetened; Water; Sugar, syrup or honey in beverage, cereal/fruit, etc.; Artificial sweetener in beverage, cereal/fruit, etc.

Mutton and/or beef stew or soup with dumpling and/or macaroni; Mutton and/or beef stew or soup with corn or any vegetables; Menudo stew; Posole/Hominy stew with mutton, beef or pork; Pinto beans with ground beef and/or chilli; Beans plain; Pinto beans with ham hocks; Refried beans; Any vegetable soup with no meat; Any chicken soup

Sweet cereals; Low-sugar cereals; High-fibre cereals; Hot cereals, cream of wheat, oatmeal, porridge, yellow, blue, white mush

Milk (1\%) or skimmed; Milk (2\%); Milk (whole); Soya milk; Milk shake or Nesquik, Smoothie; Yoghurt; Eggs; Cheese like cheddar, provolone, American or Swiss; Cottage cheese; Cream cheese; Regular Coffeemate or coffee creamer, powder or liquid; Lite or fat-free Coffeemate or coffee creamer, powder or liquid; Whipped cream; Goat's milk

Any quesadilla, including chicken, beef, etc.; Pizza; Lasagne; Macaroni cheese or fettuccine alfredo or pasta salad; Spaghetti without meat; Noodles; White rice; Fried rice, including Chinese

Blood sausage; Achee; Deer or venison; Steak, lamb or mutton baked or roast; Hamburger; Ground beef; Ground beef, Sloppy Joe, not with pasta; Meat loaf or hamburger steak; Any kind of meat ribs; Any chicken wings fried incl. KFC, Church's or Bashas, including hot wings; Any chicken fried incl. KFC, Church's or Bashas, breast, drumstick, thigh; Any baked, roasted, BBQ, boiled chicken wings; Any baked, roasted, BBQ, boiled chicken breast, drumstick, thigh; Chicken nuggets or tenders; Slim Jim; Beef jerky; Pork chops/steak fried; Bacon; Sausage links or patties; Canned Vienna Sausage, wieners; Turkey and/or ham lunch meat; Bologna, salami, lunch meat or processed meat; Light lunch meat; Spam, corned beef or bologna with fried potatoes; Spam; Corned beef; Corn dog; Turkey meat; Sardine; Tuna or tuna salad; Any fish including lake fish, fried or deep-fried; Any fish including lake fish, grilled or roasted, BBQ or baked; Shrimp, fried any

Ice cream; Ice cream cone, ice cream sandwich like Klondike; Apple or other fruit pie; Navajo cake; Cake; Banana bread; Fruit cake; Muffin; Jell-O or similar snacks; Chilchin; Candy bar; Cookie; Sandwich cookie; Rice Krispies Treat, popcorn balls or Cracker Jacks; Crisps; Baked crisps; Popcorn - regular; Popcorn - light; Sunflower seeds; Nuts; Granola or cereal bars; Gravy, regular; Gravy, lowfat recipe; Mayonnaise; Butter or margarine on bread, tortilla or vegetables; Low-fat butter or light margarine on bread, tortilla or vegetables; Peanut butter

Beer; Smirnoff Ice; Whiskey or spirits like tequila, rum, gin; Wine 
Appendix 2

Sample page of the Navajo quantitative FFQ (QFFQ)

\begin{tabular}{|c|c|c|c|c|c|c|c|c|c|}
\hline $\begin{array}{l}\text { Food } \\
\text { How often during the last } 30 \mathrm{~d} \text { did you USUALLY eat the following } \\
\text { foods and how much do you USUALLY eat at one time? }\end{array}$ & $\begin{array}{c}\text { Usual portion } \\
\text { size }\end{array}$ & Never & $1 \times /$ last $30 \mathrm{~d}$ & $2-3 \times /$ last $30 \mathrm{~d}$ & $\mid \begin{array}{c}1 \times / \text { week } \\
(4-6 \times / \text { last } 30 \mathrm{~d})\end{array}$ & $\begin{array}{c}2-3 \times / \text { week } \\
(7-13 \times / \text { last } 30 \mathrm{~d})\end{array}$ & $\begin{array}{c}4-6 \times / \text { week } \\
(14-26 \times / \text { last } 30 \text { d })\end{array}$ & $\begin{array}{c}\text { Once a day } \\
(27-31 \times / \text { last } 30 \mathrm{~d})\end{array}$ & $\begin{array}{c}\text { Twice or } \\
\text { more a day }\end{array}$ \\
\hline \multicolumn{10}{|l|}{ Breads: I'm going to ask you about different breads. } \\
\hline Fry bread & $\mathrm{BB}^{*}$ & 1 & 2 & 3 & 4 & 5 & 6 & 7 & 8 \\
\hline Navajo taco & BB & 1 & 2 & 3 & 4 & 5 & 6 & 7 & 8 \\
\hline Any taco (chicken or beef, including Taco Bell) & NB & 1 & 2 & 3 & 4 & 5 & 6 & 7 & 8 \\
\hline Navajo tortilla, white flour (grilled or stove top) & BB & 1 & 2 & 3 & 4 & 5 & 6 & 7 & 8 \\
\hline Navajo tortilla, whole wheat flour or half and half (grilled or stove top) & BB & 1 & 2 & 3 & 4 & 5 & 6 & 7 & 8 \\
\hline Navajo burger (fry bread, tortilla with hamburger) & NJ & 1 & 2 & 3 & 4 & 5 & 6 & 7 & 8 \\
\hline Navajo roast mutton sandwich & $\mathrm{Ng}$ & 1 & 2 & 3 & 4 & 5 & 6 & 7 & 8 \\
\hline Pueblo bread or home-made oven bread & Nc & 1 & 2 & 3 & 4 & 5 & 6 & 7 & 8 \\
\hline Cornbread (including kneel-down bread) & Nk & 1 & 2 & 3 & 4 & 5 & 6 & 7 & 8 \\
\hline Blue corn bread & z & 1 & 2 & 3 & 4 & 5 & 6 & 7 & 8 \\
\hline Burritos (breakfast) egg, bacon, Spam, ground beef, potato, tortilla & $\mathrm{Na}$ & 1 & 2 & 3 & 4 & 5 & 6 & 7 & 8 \\
\hline Biscuits (breakfast) egg, bacon, Spam, ground beef, potato & $x x$ & 1 & 2 & 3 & 4 & 5 & 6 & 7 & 8 \\
\hline Burrito (with bean and/or rice) no meat & $\mathrm{Na}$ & 1 & 2 & 3 & 4 & 5 & 6 & 7 & 8 \\
\hline Burrito (with bean and/or rice) with meat & $\mathrm{Na}$ & 1 & 2 & 3 & 4 & 5 & 6 & 7 & 8 \\
\hline Sausage biscuit (McDonald's, Burger King) & \# & 1 & 2 & 3 & 4 & 5 & 6 & 7 & 8 \\
\hline Chimichanga burrito & $\mathrm{Nd}$ & 1 & 2 & 3 & 4 & 5 & 6 & 7 & 8 \\
\hline Tamales & NL & 1 & 2 & 3 & 4 & 5 & 6 & 7 & 8 \\
\hline Enchiladas & NL & 1 & 2 & 3 & 4 & 5 & 6 & 7 & 8 \\
\hline Hot dog in bun & \# & 1 & 2 & 3 & 4 & 5 & 6 & 7 & 8 \\
\hline Rez dog (hotdog with fry bread \& chilli) & NJ & 1 & 2 & 3 & 4 & 5 & 6 & 7 & 8 \\
\hline Whole wheat/wheat bread (incl. rye, toasted) & \#slices & 1 & 2 & 3 & 4 & 5 & 6 & 7 & 8 \\
\hline White bread (incl. bagel, toasted) & \#slices & 1 & 2 & 3 & 4 & 5 & 6 & 7 & 8 \\
\hline Yeast bread or dinner roll & \# & 1 & 2 & 3 & 4 & 5 & 6 & 7 & 8 \\
\hline Doughnut (any kind) & \# & 1 & 2 & 3 & 4 & 5 & 6 & 7 & 8 \\
\hline
\end{tabular}

